\title{
A Case of Acute Anterior Myocardial Infarction Complicated by Acute Traumatic Brain Injury
}

\author{
$\mathrm{Li}-\mathrm{Xi} \mathrm{Ma}{ }^{1}, \mathrm{C}-\mathrm{S} \mathrm{Ma}{ }^{2}, \mathrm{Z}-\mathrm{H} \mathrm{Lu}{ }^{2}, \mathrm{Le} \mathrm{Wang}^{2}$, Y-J Liu ${ }^{2}, \mathrm{M} \mathrm{Wang}^{2}$
}

\begin{abstract}
A patient was admitted to Emergency Department within an hour of an episode of syncope followed by a fall. The electrocardiogram recorded on admission was suggestive of an extensive acute anterior myocardial infarction, and an emergency computed tomography (CT) scan of his brain showed a right scalp hematoma but no intracranial injury. He underwent primary percutaneous coronary intervention (PCI). Ten hours later, the patient reported sudden onset headache and vomiting. Repeat head CT showed left-sided intracranial hemorrhage, which required immediate neurosurgical decompression and reversal of antiplatelet and anticoagulant therapies. Three months later, the intracranial hematoma had been absorbed.
\end{abstract}

Keywords: Acute myocardial infarction, traumatic brain injury, treatment

From: ${ }^{1}$ Department of Cardiology, the First Hospital of Qinhuangdao, Hebei 066000, China ${ }^{2}$ Department of Cardiology, Beijing Anzhen Hospital, Capital Medical University, Beijing 100029, China.

Correspondence: Dr C-S Ma, Department of Cardiology, Beijing Anzhen Hospital, Capital Medical University, No 258 Wenhua Road Haigang District, Beijing 100029, China. Fax +86335 3032042, e-mail: lixiangmacn@163.com 


\section{INTRODUCTION}

Acute myocardial infarction with traumatic brain injury is not uncommon, given the clinical antithrombotic therapy caused great difficulties, for example in this case report. Be sure to carefully assess and reduce the risk of bleeding may bring antithrombotic therapy in the treatment of such patients. The case took a drug-eluting stent implantation in the culprit artery, can be taken bare-metal stent, PTCA or occlusive arterial thrombus aspiration opening. Of course, bivalirudin (1) should be preferred in such patients, from this case reports, we can draw some experience and inadequate.

\section{CASE REPORT}

A 59-year-old man was admitted to our Emergency Department within an hour of an episode of syncope followed by a fall. The electrocardiogram recorded on admission was suggestive of an extensive acute anterior myocardial infarction, and an emergency computed tomography (CT) scan of his brain showed a right scalp hematoma but no intracranial injury (Fig. 1). After informed consent was obtained, he underwent primary percutaneous coronary intervention (PCI). Coronary angiography showed complete occlusion of the proximal left anterior descending artery, with Thrombolysis in Myocardial Infarction (TIMI) Study Group grade 0 forward flow. After balloon dilatation (FIRE STAR $2.5 \mathrm{~mm} \times 15 \mathrm{~mm}$; Cordis Corporation, NJ, USA), sirolimus-eluting stents were deployed to restore coronary blood flow (EXCEL $3.5 \mathrm{~mm} \times 18 \mathrm{~mm}$; JW Medical, Shandong, China) (Figs. 2, 3). To facilitate PCI, 9,000 IU intravenous heparin was administered along with 500 micrograms tirofiban. 
The doses of heparin and tirofiban were calculated based on the patient's weight of $80 \mathrm{~kg}$, but were reduced owing to the history of trauma. After PCI, the patient reported no chest pain and there was no further bleeding from the scalp hematoma.

Ten hours later, the patient reported sudden onset headache and vomiting. Repeat head CT showed left-sided intracranial hemorrhage (Fig. 4), which required immediate neurosurgical decompression and reversal of antiplatelet and anticoagulant therapies.

Three months later, the intracranial hematoma had been absorbed (Fig. 5). As there was no further need for neurosurgical intervention, the patient was established on oral aspirin and clopidogrel once daily. The patient made an uneventful and full recovery, with no significant neurological deficit, or subsequent angina or heart failure.

\section{DISCUSSION}

In the event of an ST-segment elevation acute myocardial infarction complicated by soft tissue hematoma, priority should be given to restoring coronary blood flow by means of PCI (2). Thrombolytic therapy is contraindicated in the presence of recent bleeding $(3,4)$. In this case, extensive contralateral intracranial bleeding became evident 10 hours after PCI. This is likely to represent a contrecoup injury, which can be explained in this case by abrupt deceleration of the brain when the occiput hit a stationary object with force. Importantly, the contrecoup injury may only have occurred as a consequence of the anticoagulation given to facilitate the PCI procedure; consequently heparin and tirofiban (5) should be used with caution if there is direct evidence or increased risk of hemorrhage from other sites (6). In this 
case, antiplatelet (6) drugs were not administered in the immediate recovery period despite the deployment of drug-eluting stents, and the patient reported no further chest pain. In complex cases such as this, it is important to balance the risk of stent stenosis and myocardial reinfarction with that of recurrent intracranial hemorrhage when determining the best strategy for secondary prevention; however, there is little empiric evidence to inform clinical practice. We chose to restart antiplatelet therapy 3 months after the initial myocardial infarction and brain injury $(7,8)$, and were guided by the findings of the follow-up brain CT and the clinical condition of the patient.

\section{CONCLUSION}

Acute myocardial infarction with traumatic brain injury caused great difficulties for the clinical antithrombotic therapy. Be sure to carefully assess and reduce the risk of bleeding may bring antithrombotic therapy in the treatment of such patients.

\section{CONFLICT OF INTEREST}

All authors have no conflict of interest regarding this paper. 


\section{REFERENCES}

1. Steg PG, van 't Hof A, Clemmensen P, Lapostolle F, Dudek D, Hamon M et al. Design and methods of European Ambulance Acute Coronary Syndrome Angiography Trial (EUROMAX): an international randomized open-label ambulance trial of bivalirudin versus standard-of-care anticoagulation in patients with acute ST-segment-elevation myocardial infarction transferred for primary percutaneous coronary intervention. Am Heart J 2013; 166: 960-7.

2. Wybraniec MT, Mizia-Stec K, Krzych LJ. Neurocardiogenic injury in subarachnoid hemorrhage: a wide spectrum of catecholamine-mediated brain-heart interactions. Cardiol J 2014; 21: 220-8.

3. El Aidi H, Adams A, Moons KG, Den Ruijter HM, Mali WP, Doevendans PA et al. Cardiac Magnetic Resonance Imaging findings and the risk of cardiovascular events in patients with recent myocardial infarction or suspected or known coronary artery disease - a systematic review of prognostic. J Am Coll Cardiol 2014; 63: 1031-45.

4. Gattringer T, Niederkorn K, Seyfang L, Seifert-Held T, Simmet N, Ferrari J et al. Myocardial infarction as a complication in acute stroke: results from the austrian stroke unit registry. Cerebrovasc Dis 2014; 37: 147-52.

5. Namazi MH, Safi M, Vakili H, Saadat H, Karimi E, Bagheri RK. Comparison between Intracoronary Abciximab and Intravenous Eptifibatide Administration during Primary Percutaneous Coronary Intervention of Acute ST-Segment Elevation Myocardial Infarction. J Tehran Heart Cent 2013; 8: 132-9. 
6. El Khoury C, Sibellas F, Bonnefoy E. Is There Still a Role for Fibrinolysis in ST-Elevation Myocardial Infarction? Curr Treat Options Cardiovasc Med 2013; 15: 41-60.

7. Cuschieri JR, Drawz P, Falck-Ytter Y, Wong RC. Risk factors for acute gastrointestinal bleeding following myocardial infarction in veteran patients who are prescribed clopidogrel: GI bleeding after MI on clopidogrel. J Dig Dis 2013; 15: 195-201.

8. Desai NR, Peterson ED, Chen AY, Wiviott SD, Sabatine MS, Alexander KP et al. Balancing the risk of mortality and major bleeding in the treatment of NSTEMI patients - a report from the National Cardiovascular Data Registry. Am Heart J 2013; 166: 1043-9.e1. 


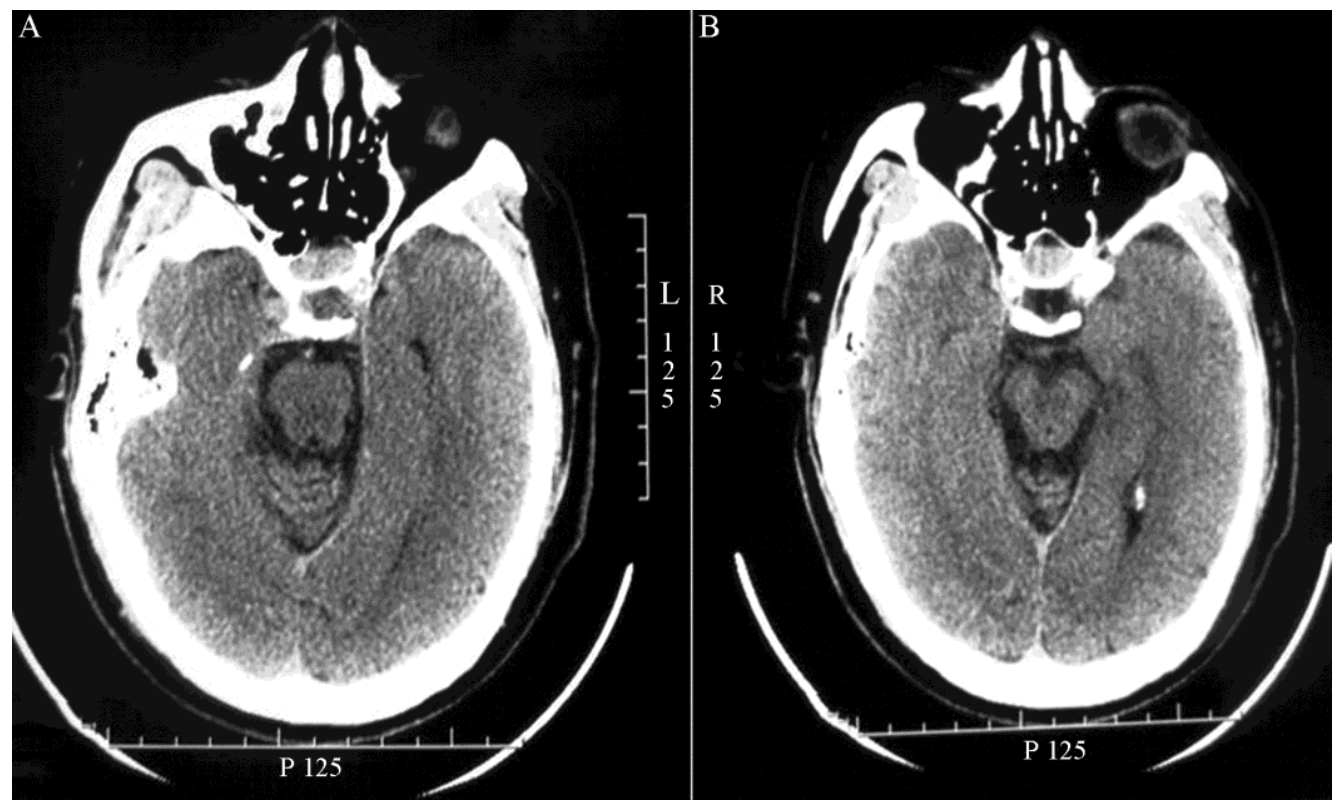

Fig.1 A, B: Emergency computed tomography examination of the head, showing a right occipital scalp hematoma, but no obvious intracranial hematoma.

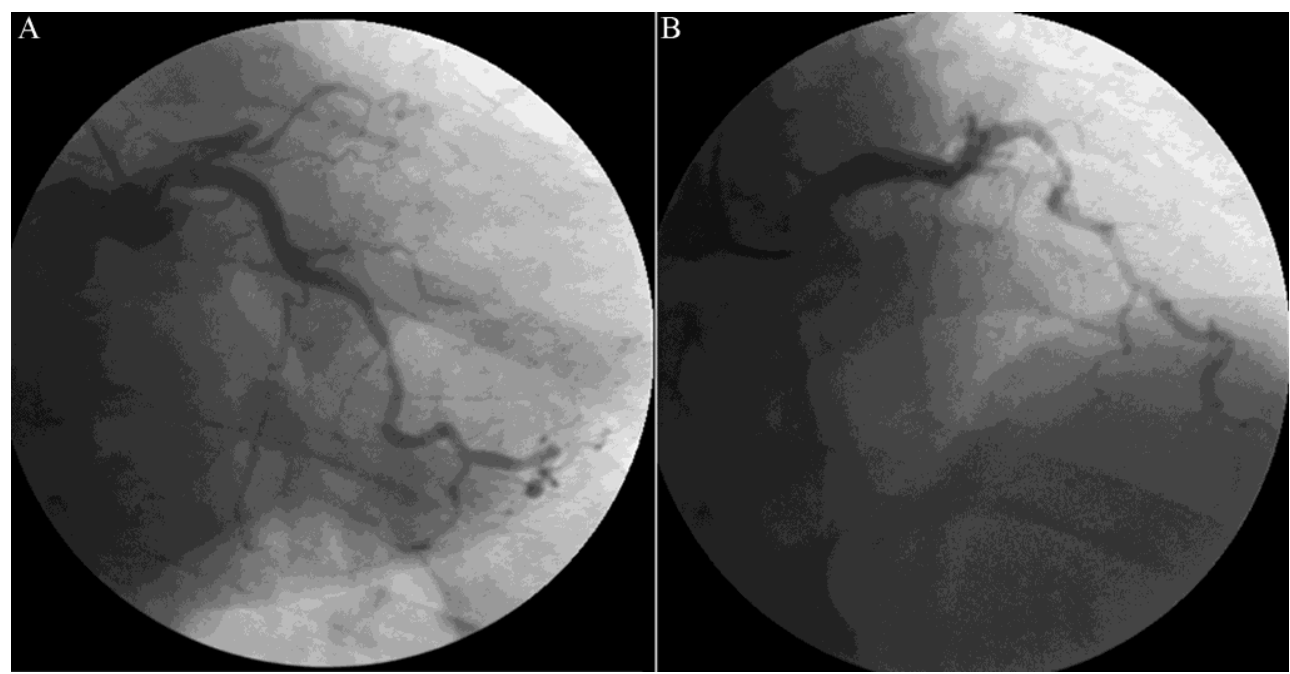

Fig.2: Emergency coronary angiography showing proximal left anterior descending artery occlusion before intervention. 


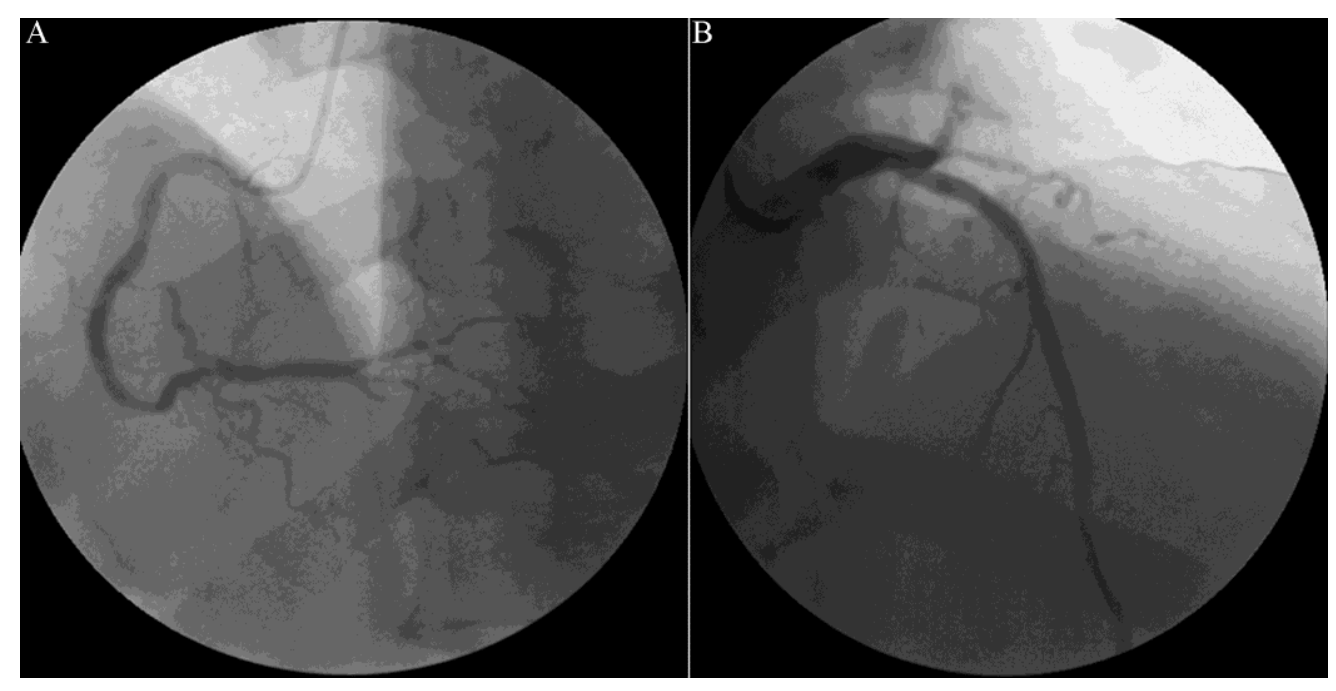

Fig.3: Left anterior descending artery PCI

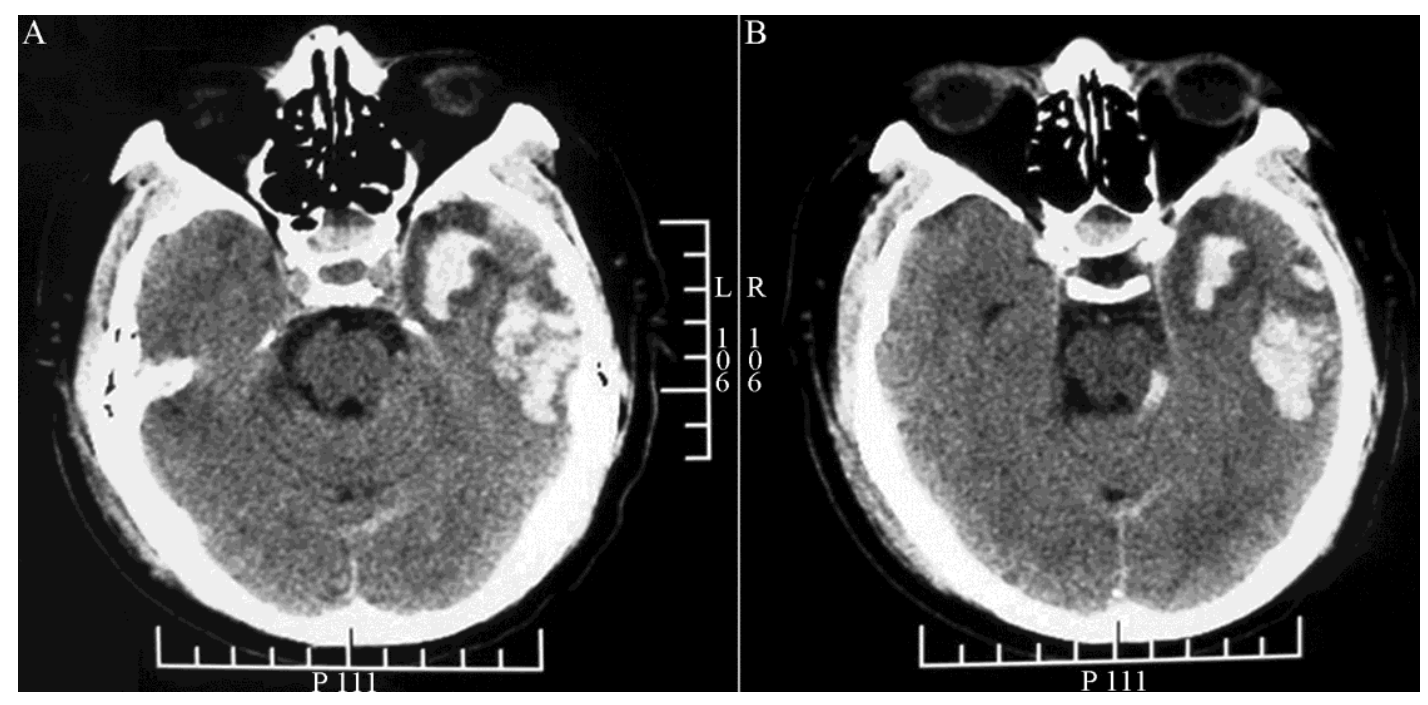

Fig.4: Left-sided intracranial hemorrhage is evident. 


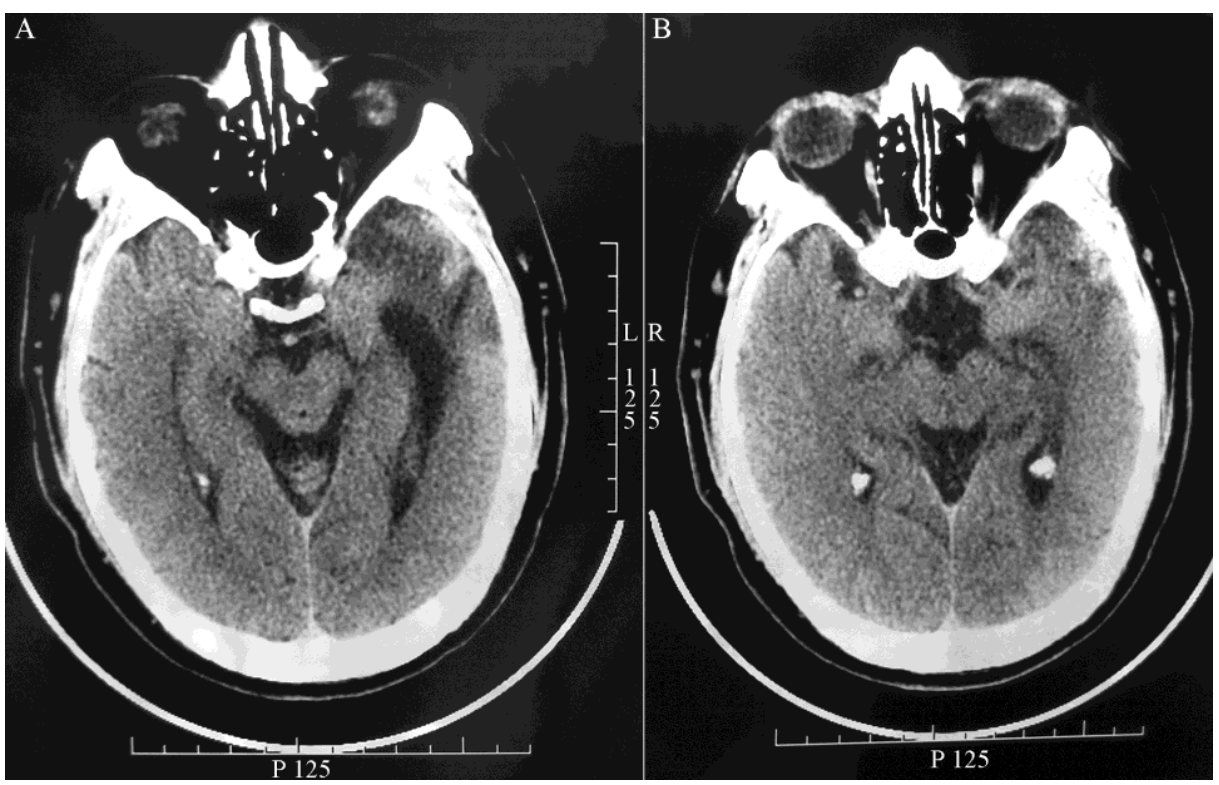

Fig.5: Showing absorption of the left-sided intracranial hematoma after 3 months. 